\title{
Study on Scheme Optimization for Energy Conservation and Emission Reduction in Beijing-Tianjin-Hebei Areas
}

\author{
Enchen WU \& Fei YAO \\ Beijing University of Chemical Technology, Beijing, China
}

\begin{abstract}
Beijing-Tianjin-Hebei integration, as a national strategy, has put forward higher demand for alternative clean energy so as to solve environmental pollution and resource exhaustion. The large scale of extreme weather such as smog, has increased people's worry about environmental pollution; while at present, there is no unified opinion on environmental solutions in Beijing, Tianjin and Hebei areas with different schemes and discrete goals, which can't adapt to the strategy of joint prevention and joint treatment. In the paper, it reanalyzes the pollutant sources of PM2.5 released by Beijing, Tianjin and Hebei, forming a new opinion. That is, energy is the main pollutant source. Based on this opinion, it aims to optimize the scheme of energy conservation and emission reduction for Beijing-Tianjin-Hebei integration. While realizing energy conservation and emission reduction, environmental pollution can be relieved as well with sustainable development and practical enforceability.
\end{abstract}

KEYWORD: Beijing-Tianjin-Hebei; energy conservation; emission reduction

\section{RESEARCH BACKGROUND}

\subsection{Background information}

Beijing-Tianjin-Hebei integration has been elevated as a national strategy. The key point of BeijingTianjin-Hebei coordinated development is to attach importance to transportation integration, cooperation among industrial chains, and construction of ecological environment, during which environment is directly related to people's life. In recent years, the constantly large scale of haze has seriously affected people's health physically and psychologically, becoming a key concern for all walks of life. Under this circumstance, construction of ecological environment and treatment of hazy weather have become urgent for Beijing-Tianjin-Hebei integration.

At present, environmental treatment is widely seen as a tough thing with low efficiency, which embodies in two aspects. First, the pollutant source is unclear; second, there hasn't been an effective and unified solution. The three places have no unified treatment solution due to the unclear pollutant source, and thus they have different explanations on pollutant sources. Smog is one of the most serious problems in environmental pollution; while PM2.5 is considered as the main reason for environmental pollution and hazy weather. In 2014, analysis on the pollutant sources of PM2.5 was released by Beijing, Tianjin and Shijiazhuang respectively.

\subsection{Analysis on the pollutant sources}

\subsubsection{Analysis on pollutants in Beijing}

Among the yearly pollutant sources of PM2.5 in Beijing, regional transmission contributes to $28 \%$ to $36 \%$, and local pollution emission accounts for $64 \%$ to $72 \%$. As for local pollutants, they mainly come from motor vehicles, coals, industrial production and fugitive dust, which accounts for $31.1 \%, 22.4 \%$, $18.1 \%$ and $14.3 \%$ respectively; besides, emissions from catering, automobile repair, livestock breeding and architectural coating and so on account for about $14.1 \%$ of PM2.5.

\subsubsection{Analysis on pollutants in Tianjin}

Among the pollutant sources of PM2.5, local emissions account for $66 \%$ to $78 \%$ and local transmissions account for $22 \%$ to $34 \%$. Among the local pollutants, fugitive dust, coals, motor vehicles and industrial production are the main sources, which accounts for $30 \%, 27 \%, 20 \%$ and $17 \%$ respectively; while other emissions from catering, automobile repair, livestock breeding, architectural coating as well as sea salt particles account for $6 \%$.

\subsubsection{Analysis on pollutants in Shijiazhuang}

Among the sources of PM2.5, regional pollution transmission accounts for $23 \%$ to $30 \%$. About $70 \%$ 
to $77 \%$ pollutants come from local pollution, and various local pollutant sources are as follows. Coal accounts for $28.5 \%$, industrial production accounts for $25.2 \%$, fugitive dust accounts for $22.5 \%$, motor vehicles account for $15 \%$, and other emissions from materials burning, catering and agriculture account for $8.8 \%$.

\subsection{Analysis on pollutant sources}

From the analysis on pollutant sources of PM2.5, different explanations have been presented by Beijing, Tianjin and Shijiazhuang. According to Beijing, automobile exhaust is the main reason for PM2.5; while fugitive dust is seen as the main reason for pollution in Tianjin; besides, firing coal is considered the main reason for PM2.5 in Shijiazhuang. Exploration on pollutant sources is to improve environmental treatment efficiency to maximum degree by centralizing resources; however, it has resulted in different focuses on treatment in the three places due to their different explanations, which will affect the scheme optimization under Beijing-Tianjin-Hebei integration.

Under the background of Beijing-Tianjin-Hebei integration, the treatment scheme has not been unified with more serious and complicated pollutant sources.

\subsection{Energy is the main reason}

Through reanalysis on the data of pollutant sources released by the three places, we find among the sources of PM2.5, local transmission accounts for $30 \%$; while local pollution from coal firing, motor vehicles and industrial production accounts for $70 \%$, all of which are pollution emissions resulted from energy consumption. That is to say, the sources of PM2.5 consist of 30\% pollutants transmitted from other places and $70 \%$ local pollution emissions from energy consumption. With the data above, we take Beijing, Tianjin and Hebei as a whole to study the problem. The so-called pollutants from other places also contain $70 \%$ pollution caused by energy emission. That is, environmental pollution caused by energy accounts for $70 \%$ totally; while environmental pollution caused by other pollutants such as fugitive dust accounts for $30 \%$.

According to management science, there is a law called Pareto law, from which we can find the most key point affecting the problem. That is, environmental pollution is caused by energy emission. Pollutant sources can become clearer if we change our perspective on the problem. The effect on environmental protection will be more significant if the $70 \%$ pollution caused by energy consumption can be relieved effectively, compared to the $30 \%$ pollution brought by local emissions from motor vehicles, fugitive dust and coal firing.

\section{STATUS ANALYSIS}

\subsection{Energy consumption}

In China, the energy consumption of GDP for per ten thousand yuan has been reduced to 0.76 ton of standard coal per ten thousand yuan in 2012 from the previous 1.47 tons of standard coal per ten thousand yuan in 2000 with significant effect. However, the total quantity of energy consumption has been increased to 37.5 billion tons of standard coals in 2013 from 14.5531 billion tons of standard coals in 2000 , increasing by 1.6 times with annual increase rate of $7.6 \%$. Meanwhile, the consumption volume of natural gas has also been increased to 2.175 billion tons of standard coal in 2013 from the 382.6 million tons of standard coal in 2000, increasing by 5.8 times with annual increase rate of $16 \%[1]$. The data has been shown in the table below specifically.

Table 1 The total consumption amount of energy and natural gas in recent years (unit: ten thousand tons of standard coal)

\begin{tabular}{|c|c|c|}
\hline Indicators & $\begin{array}{c}\text { Total consumption of } \\
\text { natural gas }\end{array}$ & $\begin{array}{c}\text { Total consumption of } \\
\text { energy }\end{array}$ \\
\hline 2000 & 3201.68 & 145530.9 \\
\hline 2003 & 4594.8 & 183791.8 \\
\hline 2006 & 7501.6 & 258676.3 \\
\hline 2009 & 11959.23 & 306647.2 \\
\hline 2012 & 18810.06 & 361732 \\
\hline 2013 & 21750 & 375000 \\
\hline
\end{tabular}

*Data source: national data

\subsection{Measures for emission reduction}

In order to deal with the constantly deteriorating environment, a series of measures have been adopted, which mainly cover treatment on two aspects. One is to reduce emission and relieve environmental pollution by controlling total energy consumption. From the actual situation in recent years, the main measure is to control GDP consumption per ten thousand yuan so as to control the total energy consumption; while the total energy consumption has been increased constantly with the development of economy, which can be reflected from the data above.

The second is to reduce energy emission per unit. From the data above, we can see the main contribution comes from natural gas. That is, unit emission of energy consumption has been reduced by using natural gas, and thus the environmental pollution has also been relieved. Natural gas is seen as a clean energy without pollution. Therefore, a wide use of natural gas may have some effect at the 
moment, but it may be not appropriate for the new integrated situation in Beijing-Tianjin-Hebei area.

\subsection{Potential risks}

As is shown above, the growth of natural gas consumption is far more than the growth of total energy consumption. Currently, China is rich in coal, but it has less oil and gas, so these rare resources should be protected preferentially with control on the consumption of natural gas. The wide employment of natural gas will shorten the usage term of natural gas greatly.

Taking the data in 2002 as an example, the reserve of natural gas that year was 20.169 billion cubic meter, and the consumption volume was 29.2 billion cubic meter, so it could be used for about 69 years; while in 2012, the reserve of natural gas was 43.79 billion cubic meter, that is to say, natural gas in our country will be exhausted in the coming 30 years. In fact, the reserve of natural gas is limited, while consumption volume is increasing year by year. Thus, according to the trend, our country will face serious energy crisis in the following decades. Large scale of imported gas may bring unstable factors for society, which is bad for national energy security. Energy conservation means emissions from rare resources should be reduced to ensure a sustainable development with longer tenure of energy use. Although the emissions can be reduced by using natural gas widely, it is against with the initial goal of energy conservation. Besides, it may also result in side effect on economic development with a rising price for energy resources.

\section{SCHEME OPTIMIZATION}

Energy conservation and emission reduction is indispensable in realizing the integration among Beijing, Tianjin and Hebei and establishing an ecological environment. A new scheme should be explored to adapt to the integration status quo while maintaining sustainable development. In the paper, the existing scheme has been optimized to realize the expected effect. Generally speaking, two aspects need to be optimized for the scheme. One is the goal, and the other is the means.

\subsection{Optimization of the goal}

In order to optimize the scheme, the goal should be clarified firstly. In the past, the goals in Beijing, Tianjin and Hebei are different because of different pollutant sources. For example, the goal in Beijing is to deal with automobile exhaust since the major pollution is from automobile exhaust. The second is disunity between structure and allocation plan. It is uncertain about the technology and resources used to solve present problems. Although there was certain range and rough goal for the emission reduction previously, which pollutant source accounts for the largest proportion is not sure. Therefore, the major pollutant source needs to be found out and optimized as the largest goal. However, situations are different in the three places, so it will result in some new problems by taking them into consideration together. The automobile exhaust problem in Beijing may be not the major problem in Tianjin and Hebei. Besides, even though the major pollutant source in Beijing is found out, it only accounts for $31 \%$; while the rest $70 \%$ still needs to be solved. The previous blur goal was due to the uncertain pollutant source, but nownew pollutant sources are divided by energies, so the goal can become clear for the clear pollutant source.

Another problem for goal optimization is to realize the double goal of emission reduction and sustainable development. In the past, we only need to reduce emissions, but now we should ensure energy conservation while reducing emission, which is a double goal. As for the goal itself, it has some problems. One is that the goal is not clear. Before we only to realize the single goal of emission reduction, which can be obtained by extensive use of natural gas so as to reduce environmental pollution; however, natural gas itself belongs to rare resources, so the large scale of usage will result in energy crisis, which will be bad for sustainable development. Therefore, the environmental pollution can't be solved effectively and obviously abide by the previous scheme since it may lead to a rapid exhaustion of energy. The new goal has two features, which make it clear and effective. The clearness of the goal lies in that the goal is consistent in Beijing, Tianjin and Hebei; and the effectiveness means that effect can be seen if the goal is realized in BeijingTianjin-Hebei areas since pollution comes from energy accounts for $70 \%$ of the total pollutant sources. The multiple goals can be satisfied at the same time. In the past, realization of environmental goal may affect the goal of sustainable development, but now the two goals can be realized at the same time.

\subsection{Optimization of means}

The second aspect of scheme optimization is to optimize the means of realizing goals. Since energy is considered the main pollutant source, clean coal is suggested in the paper to be used as main energy to optimize the goal. Coal was known as dirty energy before, which was wrong scientifically because the division of clean energy should be based on its pollution severity on environment. That is, it should be classified by emissions. However, emission pollution is also determined by technological level partially, so emission technology should also 
considered when classifying clean energies instead of classifying them by their varieties. For a long time, coal had always been seen as dirty energy for its high emission standard; while now emission pollution from coal is greatly reducedfor the higher technological level of cleaning coal, and the pollution is even less than that from natural gas. Technically, we can use clean coal as clean energy to relieve environmental pollution[2]. For example, electronic energy is a secondhand energy with wide application, so if emissions from power generation by coal can reach a clean effect without pollution, then environment can be protected well from the perspective of energy. At present, the existed technology has been applied to practice widely.

IGCC power generation technology has realized clean emission already. The net efficiency of IGCC power generation can reach $43 \%$ to $45 \%$ [3], and the emission of pollutants is only $1 / 10$ of that from conventional coal-fired power station. The desulphurization efficiency can reach to $99 \%$ with about $25 \mathrm{mg} / \mathrm{m} 3$ of sulfur dioxide emission. The emission of nitrogen oxide is only $15 \%$ to $20 \%$ of conventional power station. The standard emission of sulfur dioxide prescribed by the State is $35 \mathrm{mg} / \mathrm{m} 3$ for natural-gas boiler and compressor-turbine unit. Thus, IGCC has realized the effect of zero emission, which is better than that from natural-gas boiler.

\subsection{Examples in application}

The technology mentioned above has been applied to practice widely. In 2014, the gross capacity generated by IGVV power station unit in Tianjin Huaneng was 1.08 billion KWH, which has been used for 5543 hours totally[4]. The actual measurement of sulfur emission and dust emission by Huaneng Tianjin IGCC was all less than $1 \mathrm{mg} / \mathrm{m} 3$, and the sulfur removal efficiency was above $99.99 \%$. The emission of nitrogen oxide from natural-gas turbine unit is less than $50 \mathrm{mg} / \mathrm{m} 3$.

\section{CONCLUSION AND SUGGESTIONS}

\subsection{Conclusion and summary}

In this paper, energy is considered the main reason for environmental pollution such as hazy weather in Beijing-Tianjin-Hebei areas, so the author advocates using clean coal as the main energy to optimize the scheme for energy conservation and emission reduction. The specific reasons are listed below.

First, it is beneficial for a sustainable development. The reserve of coal in China is far more than natural gas.

Second, it is good for national energy security.

Third, it is beneficial to relieving environmental deterioration.

Fourth, it is beneficial to reducing cost.

By taking clean coal as the target energy to optimize the scheme, all of the four advantages above can be achieved well, which adapts to the new situation of Beijing-Tianjin-Hebei integration.

\subsection{Suggestions for development}

Given the opinions above, some suggestions are proposed here.

First, the technology of coal cleaning should be developed vigorously.

Second, other alternative energies should be developed actively.

Third, use of rare resources should be reduced.

\section{REFERENCES}

[1] National Bureau of Statistics.2012. China Statistical Yearbook. Beijing, China Statistics Press.

[2] Bai Yunfeng \& Yipeng, Du \& Shaozhong, Wangying. 2014. Clean Technology for Coal Use. Chinese Strategic Emerging Industry.15:56-58.

[3] Qu Weiping. 2010. Combine Technology of CCS and IGCC for Power Generation by Clean Coal. Mechanical \& Electrical Integration Technology Home and Abroad, 01:58-63+65.

[4] Yan Liyang \& Zhaoxiao. 2014-08-07011. Can be coal-fired emission lower than natural gas? China Environmental News,08-07011 